Jurnal Penelitian Pendidikan Geografi Volume 4 Nomor 2 April 2019

\title{
DESKRIPSI HASIL PETANI JAGUNG MASYARAKAT LOKAL DAN MASYARAKAT TRANSMIGRASI ASAL JAWA DI DESA WAKOBALU AGUNG KECAMATAN KABANGKA KABUPATEN MUNA
}

Dewi Satria ${ }^{1}$

${ }^{1}$ Alumni Jurusan Pendidikan Geografi FKIP UHO

\begin{abstract}
Abstrak : Rumusan masalah dalam penelitian ini yaitu Bagaimana deskripsi hasil petani jagung masyarakat lokal dan masyarakat transmigrasi asal jawa di Desa Wakobalu Agung Kecamatan Kabangka Kabupaten Muna? Dan Faktor-faktor apa yang menyebabkan perbadaan hasil petani jagung masyarakat lokal dan masyarakat transmigrasi asal jawa di Desa Wakobalu Agung Kecamatan Kabangka Kabupaten Muna. Penelitian ini menggunakan metode analisis kualitatif dengan pendekatan kualitatif deskripstif. Hasil penelitian diketahui terdapat perbedaan antara hasil pertanian jagung antara masyarakat lokal dan masyarakat transmigrasi dari Jawa. Adapun hasil petani jagung pada masyarakat lokal hanya berkisar antara 100 hingga $250 \mathrm{~kg}$ per musimnya sedangkan pada masyarakat transmigrasi mencapai kisaran 250 hingga $400 \mathrm{~kg}$ per musimnya. Adapun faktor yang mempengaruhi perbedaan hasil pertanian jagung antara masyarakat lokal dan masyarakat transmigrasi dari Jawa yaitu terletak pada pengelolaan lahan pertanian yang dilakukan yaitu pada masyarakat transmigarsi dari Jawa dalam mengelola lahan dan usaha pertanian jagung menggunakan pestisida pada saat sebelum melakukan penanaman dan melakukan pemupukan pada saat perawatan dan pemeliharaan tanaman jagung sedangkan pada masyarakat lokal tidak menggunkan pestisida pada benih sebelum penanaman dilakukan dan juga pemberian pupuk tetapi hanya mengandalkan kadar humus yang ada pada tanah lahan pertanian. Kesimpulan dalam penelitian ini terdapat perbedaan hasil pertanian antara masyarakat lokal dan masyarakat transmigrasi dan perbedaan hasil pertanian jagung dipengaruhi oleh faktor pengelolaan dan pemberdayaan hasil pertanian yang dilakukan oleh masyarakat lokal maupun masyarakat transmigrasi dari Jawa.
\end{abstract}

Kata Kunci: hasil pertanian jagung, Masyarakat lokal, Transmigrasi dari Jawa 
Jurnal Penelitian Pendidikan Geografi Volume 4 Nomor 2 April 2019

\title{
DESCRIPTION OF THE RESULTS OF CORN FARMERS FROM THE LOCAL COMMUNITIES AND THE TRANSMIGRATION COMMUNITY FROM JAVA IN THE VILLAGE OF WAKOBALU AGUNG, KABANGKA SUB-DISTRICT, MUNA REGENCY
}

\author{
Dewi Satria ${ }^{1}$
}

${ }^{1}$ Alumni Of Geography Education FKIP UHO

\begin{abstract}
The formulation of the problem in this study is how to describe the results of the corn farmers of the local community and the transmigration community from Java in the Wakobalu Agung Village, Kabangka Sub-district, MunaRegency? And what factors cause the results of local farmers and transmigration communities from Java in the Wakobalu Agung village, Kabangka Sub-district, Muna Regency. This research uses qualitative analysis method with descriptive qualitative approach. The results of the study revealed that there was a difference between the results of corn farming between local communities and transmigration communities from Java. The results of corn farmers in local communities only range from 100 to $250 \mathrm{~kg}$ per season, while in transmigration communities reach the range of 250 to $400 \mathrm{~kg}$ per season. The factors that influence the difference in corn farming results between the local community and the transmigration community from Java are on the management of agricultural land carried out. Transmigration communities from Java manage their corn farms and businesses using pesticides at the time before planting and fertilizing during the maintenance and maintenance of corn plants, while the local people do not use pesticides on the seeds before planting and fertilization but only rely on humus on agricultural land. The conclusion of this study is that there are differences in agricultural yields between local communities and transmigration communities and the differences in maize agricultural yields are influenced by factors of management and empowerment of agricultural products carried out by local communities and transmigration communities from Java.
\end{abstract}

\section{Keywords: corn farming, local communities, transmigration from Java}

\section{PENDAHULUAN}

Indonesia merupakan negara agraris yang mengandalkan sektor pertanian sebagai mata pencaharian utama penduduk, maupun sebagai penopang pembangunan. Sektor pertanian merupakan penopang perekonomian Indonesia, karena pertanian memberikan porsi yang cukup besar dalam memberikan sumbangan untuk pendapatan Negara, sebagai pasar yang potensial bagi produk - produk dalam negeri baik untuk barang produksi maupun barang konsumsi, terutama produk yang dihasilkan oleh subsektor tanaman pangan.

Pertanian merupakan salah satu sektor usaha masyarakat yang dapat menunjang kebutuhan pokok masyarakat Indonesia. Pertanian merupakan kegiatan pengolahaan sumber daya hayati yang dilakukan manusia untuk menghasilkan bahan pangan, bahan baku industri, atau sumber energi, serta untuk mengelolah lingkungan hidupnya. Kegiatan pemanfaatan sumberdaya hayati dalam lingkup pertanian biasanya dipahami 
dengan dengan istilah bercocok tanam (Wawan, 2016: 7).

Masyarakat lokal merupakan masyarakat yang sudah lama menetap disuatu wilayah dan sudah melangsungkan pernikahan serta budaya dan adat istiadat secara turun temurun. Masyarakat lokal merupakan masyarakat yang pertama yang mendiami suatu wilayah dan terus berproses dalam tujuan pengembangan wilayah tersebut. Penduduk asli suatu wilayah cenderung memiliki pengetahuan yang kompleks akan wilayah yahg dimilikinya (Rifai, 2017: 3)

Masyarakat transmigrasi adalah masyarakat yang melakukan perpindahan dari daerah Jawa ke desa Wakobalu agung Kecamatan Kabangka Kabupaten Muna. Transmigrasi dilakukan untuk berbagai kepentingan, diantara kepadatan penduduk, persoalan lapangan pekerjaan, wilayah, serta tentang tersedianya sumber daya alam. Transmigrasi seyogyanya erat kaitanya dengan tujuan negara dalam memberikan kesejahteran rakyatnya. Perpindahan masyarakat tersebut menyebabkan perpaduan budaya dan pengalaman serta hal-hal baru yang dapat memberikan hal positif bagi masyarakat lainya. Masyarakat yaang melakukan proses transmigrasi seyogyanya dibelai oleh ilmu pengetahuan yang mumpuni, baik diperoleh dari pelatihan-pelatihan yang dilakukan pemerintah, pihak swasta, ataupun pengetahuan yang bersifat pengalaman dan otodidak (Yuminarti, 2017: 17).

Pemerintah melaksanakan proses tranmigrasi dengan berbagai tujuan diantaranya adalah sebagai berikut: a). Pemerataan persebaran penduduk, b). meningkatkan potensi ekonomi, c). Pemanfaatan sumberdaya yang merata, d). Memperkuat pertahanan dan keamanan nasional, e). Pemerataan pembangunan, f).
Meningkatkan taraf hidup masyarakat, g). Menigkatkan persatuan dan kesatuan banagsa, h). Mengatasi kemiskinan khususnya didaerah asal transmigrasi (Dwiyantoro, 2007: 12).

Jagung merupakan salah satu komoditas utama tanaman pangan, yang mempunyai peranan strategis dalam pembangunan pertanian dan perekonomian Nasional khususnya Kabupaten Muna. Komoditas ini mempunyai fungsi multiguna, baik untuk konsumsi langsung maupun sebagai bahan baku utama industri pakan serta industri pangan. Pentingnya peranan komoditi jagung terhadap perekonomian nasional khusunya Kabupaten Samosir yang telah menempatkan jagung sebagai kontributor terbesar kedua terhadap Produk Domestik Bruto (PDB) setelah padi dalam subsektor tanaman pangan. Hampir seluruh bagian dari tanaman jagung mempunyai potensi nilai ekonomi, buah jagung pipilan sebagai produk utamanya merupakan bahan baku utama $(51 \%)$ industri pakan, selain dapat dikonsumsi langsung dan sebagai bahan baku industri pangan, daun, batang, kelobot dan tongkolnya dapat daerah di Sulawesi Tenggara dengan pemanfaatan lahan disektor pertanian adalah terdapat di Kecamatan Kontukowuna.

Kebutuhan jagung di Indonesia saat ini cukup besar, yaitu lebih dari 10 juta ton pipilan kering pertahun. Konsumsi jagung terbesar adalah untuk pangan dan industri pakan ternak, karena sebanyak $51 \%$ bahan baku pakan ternak adalah jagung. Dari sisi pasar, potensi pemasaran jagung terus mengalami peningkatan, hal ini dapat dilihat dari semakin berkembangnya industri peternakan yang pada akhirnya meningkatkan permintaan jagung sebagai bahan pakan ternak, berkembang pula produk pangan dari jagung dalam bentuk tepung jagung di kalangan masyarakat. 
Produk tersebut banyak dijadikan untuk pembuatan produk pangan (Budiman, 2012).

Cara bercocok tanam masyarakat transmigrasi dengan cara pembabatan atau pembersihan lahan baru secara gotongroyong sampai penanaman jagung dan sebelum proses penanaman dimulai terlebih dahulu memilih bibit yang bagus barulah memulai proses penanaman jagung sampai selesai. Setelah itu dirawat sampai proses pemanen tiba dengan kurung waktu dua sampai tiga bulan, dengan jenis jagung yang mereka tanam yaitu jagung harum manis yang cepat laku dipasaran, sedangakan prose pemanenan jagung tidak jauh beda dengan masyarakat lokal. Yang membedakan hasil tani jagung masyarakat lokal dengan masyarakat trans yaitu dari segi cara pembersihan lahan dan cara pemilihan bibit jagung. Untuk masyarakat lokal mereka menanam jagung tidak disesuaikan dengan kondisi pasaran, seperti jagung hibrida dan jugung harum manis, sementara masyarakat trans mereka melihat kondisi pasaran jagung contohnya seperti jagung harumanis dipasaran sangat laku di bandingkan jagung hibrida, tidak hanya itu jangung harum manis prosesnya cepat dengan jangka waktu 2 - 3 bulan sedangkan jagung hibrida prosenya lama membutuhkan waktu sampai 4 bulam baru bisa panen.

\section{METODE PENELITIAN}

\section{a. Waktu dan Tempat}

Penelitian ini dilaksanakan pada Bulan Mei 2018, bertempat di Desa Wakobalu agung Kecamatan Kabangka Kabupaten Muna.

\section{b. Pendekatan dan Metode Penelitiaan}

Jenis penelitian ini adalah penelitian deskriptif kualitatif. Deskriptif kualitatif yaitu yaitu mendeskripsikan secara alamiah mengenai perbedaan hasil usaha tani jagung masyarakat lokal dan masyarakat transmigrasi asal Jawa di Desa Wakobalu agung Kecamatan Kabangka Kabupaten Muna.

\section{c. Informan Penelitian}

Dalam penelitian kualitatif tidak dimaksudkan untuk membuat generalisasi dari hasil penelitiannya. Oleh karena itu, pada penelitian ini tidak dikenal adanya populasi (Suyanto, 2015: 171). Subyek dalam penelitian ini ditentukan secara sengaja.Subyek penelitian menjadi informan yang yang akan memberikan berbagai informasi yang diperlukan selama proses penelitian. Informan merupakan orang yang benar-benar mengetahui suatu persoalan atau permasalahan tertentu. Darinyalah peneliti memperoleh informasi yang jelas, akurat dan terpercaya, baik berupa pernyataan, keterangan-keterangan, serta data-data yang dapat membantu dalam memenuhi permasalahan. Informan penelitian (Suyanto, 2005: 172) meliputi beberapa macam, yaitu: 1). Informasi kunci yang merupakan mereka yang mengetahui dan memiliki berbagai informasi pokok yang diperlukan dalam penelitian, 2) informan utama merupakan masyarakat yang terlibat langsung dalam interaksi sosial yang diteliti, 3) informan tambahan merupakan mereka yang dapat memberikan informasi walaupun tidak langsung terlibat dalam interaksi sosial yang diteliti.

\section{GAMBARAN UMUM LOKASI PENELITIAN}

\section{Keadaan Geografi}

Desa Wakabalu Agung merupakan salah satu Desa yang terletak di Kecamatan Kabangka, Kabupatun Muna, yang mendiami sebagian daratan dengan berbagai kompleksitas penduduk dan kehidupannya. Sebagai mana halnya desa-desa lain Desa Wakabalu Agung memiliki batas wilayah yaitu: 
a. Sebelah Utara berbatasan dengan Desa Wasugi

b. Sebelah Timur berbatasan dengan Desa Lapilibangka

c. Sebelah Selatan berbatasan dengan Desa Kabangka

d. Sebelah Barat berbatasan dengan Desa Sarimulyo

Secara administrasi wilayah Desa Wakabalu Agung terbagi atas 3 (tiga) dusun yaitu Dusun I,DusunII dan Dusun III. Luas wilayah Desa Wakabalu Agung menurutpengukuran adalah $187 \mathrm{Ha} / \mathrm{m}^{2}$. (Sumber Kantor Wakabalu Agung 2018).

\section{- Kondisi Demografis}

Keadaan dan jumlah penduduk yang mendiami Desa Wakabalu Agung hingga Bulan Mei Tahun 2018 berjumlah 2400 jiwa yang terdiri dari 1.336 Laki-laki dan 1.064 perempuan dengan jumlah Kepala Rumah Tangga 584.

Masyarakat Desa Wakobalu Agung sebagian besar mata pencaharianya berkecimpung di bidang pertanian.Hal itu sangat didukung potensi alamnya yang sangat cocok untuk daerah pertanian. Selain petani penduduk Desa Wakobalu Agung juga berprofesi sebagai pedagang, PNS, wiraswasta dan tukang.

\section{HASIL DAN PEMBAHASAN}

\section{A. Perbedaan Hasil Petani Jagung Masyarakat Lokal dan Masyarakat Transmigrasi Asal Jawa di DesaWakobalu agung Kecamatan Kabangka Kabupaten Muna}

Desa Wakobalu Agung sebagai daerah transmigran terdapat dua kelompok masyarakat yaitu masyarakat lokal dan masyarakat sebagai pendatang. Pada umunya masyarakat Desa Wakobalu Agung berprofesi sebagai petani termasuk petani jagung. Masyarakat transmigran dan masyarakat lokal dan berinteraksi telah berbaur satu sama lain, suku Jawa masyarakat transmigrasi di desa Wakobalu Agung dalam melakukan usaha dan berprofesi sebagai petani tidak mengalami masalah yang cukup berat untuk beradaptasi karena suku jawa memiliki beberapa kesamaan dalam hal pengelolaan pertanian.

Adapun kesamaan baik masyarakat lokal maupun masyarakat transmigran seperti terlihat pada pembukaan lahan baru saat berkebun. Sama halnya dengan etnis

Muna, mereka juga melakukan ritualritual tertentu sebelum membuka lahan baru dengan mengadakan $\boldsymbol{k}$ a ago-ago yang dalam istilah suku Muna yang berarti

meminta izin kepada roh-roh halus yang menempati tempat tersebut. selain itu

fungsika ago-ago ini juga untuk mengusir roh-roh jahat yangmenghuni tempat tersebut. Ritual ini dipimpin oleh seseorang yang mempunya keahlian khusus (paranormal) atau orang tua yang dituakan dan dianggap mampu dalam menjalankan ritual ini.

Namun seiring berjalannya waktu ritual ini dari tahun ketahun sudah jarang dilakukan oleh penduduk lokal karena mungkin acara ritual tradisional seperti ini sudah dianggap tidak sesuai lagi dengan jaman sekarang sehingga sudah jarang betul dilakukan. Tetapi ritual ini tidak pula ditinggalkan karena masih ada beberapa yang masih mempercayainya. 
Jurnal Penelitian Pendidikan Geografi Volume 4 Nomor 2 April 2019

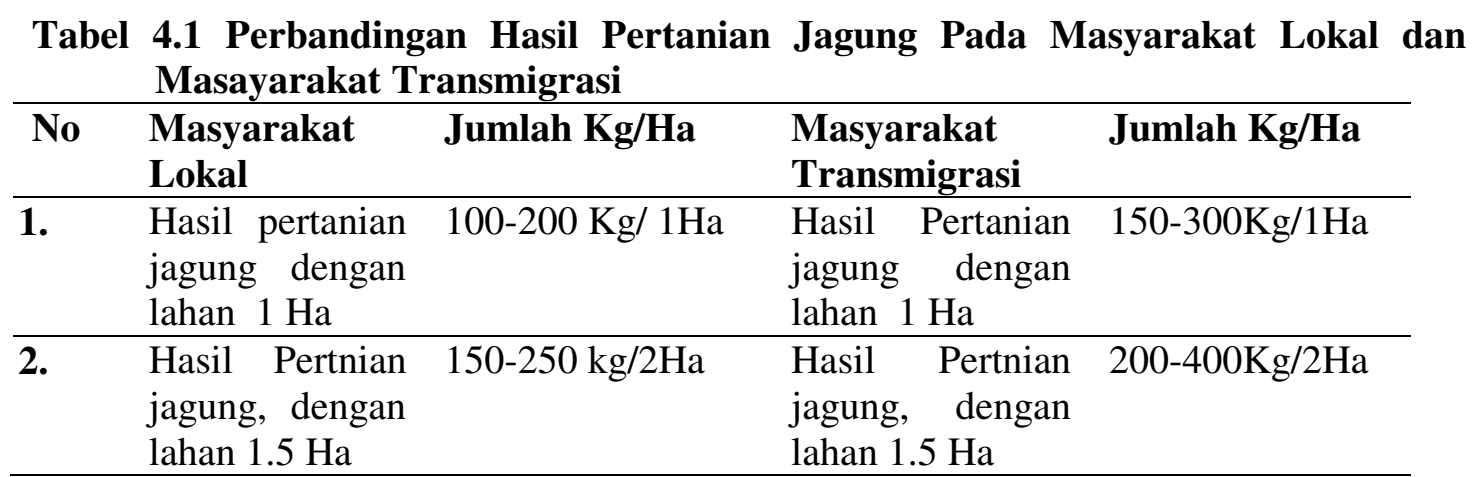

Sumber: Diolah dari hasil wawancara 2018

\section{B. Faktor Penyebab Perbedaan Hasil Petani Jagung Masyarakat Lokal dan Masyarakat Transmigrasi Asal Jawa di Desa Wakobalu Agung}

Berdasarkan profesi pekerjaan sebagai petani jagung maka terdapat faktor-faktor yang menyebabkan perbedaan hasil panen jagung berbeda antara masyarakat lokal dengan masyarkat transmigrasi.Faktor penyebab hasil pertanian jagung tersebut dapat dilihat melalui tahapan-tahapan pelaksanaan usaha pertanian mulai dari pembukaan lahan, pembersihan lahan, pembibitan/penyamaian, penanaman, pemupukan, pemeliharaan, panen dan pasca panen. Adapun lebih jelasnya mengenai faktor-faktor yang menyebabkan perbedaan hasil usaha tani pada masyarakat lokal dengan masyarakat

transmigrasi dari jawa dapat dilihat melalui tahapan-tahapan pengelolaan lahan pertanian oleh petani jagung yang dilakukan pada masayarakat lokal dan masyarakat jawa dapat dijabarkan sebagai berikut:

\section{Pembukaan Lahan}

Pada pembukaan lahan sebagaimana dijelaskan di atas bahwa pada dasarnya masyarakat jawa dan masyarakat muna ketika membuka lahan baru sebagai tempat pertanian terdapat kesamaan yaitu melakukan ritual-ritual tertentu sebelum membuka lahan baru dengan mengadakan $\boldsymbol{k} \boldsymbol{a}$ ago-ago yang dalam istilah suku Muna yang berarti meminta izin kepada roh-roh halus yang menempati tempat tersebut. selain itu fungsi $\boldsymbol{k a}$ ago-ago ini juga untuk mengusir roh-roh jahat yang menghuni tempat tersebut. Ritual ini dipimpin oleh seseorang yang mempunya keahlian khusus (paranormal) atau orang tua yang dituakan dan dianggap mampu dalam menjalankan ritual ini.

Berdasarkan keterangan dan penjelasan di atas baik masyarakat lokal maupun masyarakat transmigrasi jawa memiliki kepercayaan dan kebiasaan yang sama pada saat membuka lahan baru yaitu adanya ritual magis yang dilakukan sebagai bagian dari kepercayaan yang dipengaruhi animsime dan dinamisme kapercayaan tentang roh-roh atau mahluk halus yang mendiami suatu wilayah tempat membuka lahan baru maka perlu dilakukan ritual untuk mengusir atau memberi tahu kepada mahluk ghaib untuk tidak mengganggu manusia ketika mengelola lahan pertanianya.

\section{$>$ Pembersihan Lahan}

Proses pembersihan lahan pada masyarakat lokal desa Wakobalu Agung Kecamatan Kabangka Kabupaten Munamasih cukup tradisonal dengan menggunakan prinsip kegotong 
royongan.Kondisi yang sama juga dilakukan oleh masyarakat transmigrasi dari jawa dalam melakukan pembersihan lahan juga dilakukan dengan bersama-sama dengan semangat gotong royong.

Berdasarkan keterangan-keterangan dalam wawancara maka dapat menggambarkan bahwa baik masyarakat lokal maupun masyarakat transmigrasi masih sangat memegang prinsip kegotong royongan dalam melakukan pembersihan lahan pertanian agar siap untuk ditanami tanaman jagung.

\section{Penyamain/Pembibitan}

Setelah proses pembersihan lahan selesai tahap selanjutnya adalah proses penyedian bibit untuk ditanam atau dikenal dengan pembibitan atau penyemaian. Pada tahapan ini adalah proses mempersiapkan bibit jagung yang siap ditanami. Dalam tahapan pembibitan atau penyamaian pada masyarakat lokal pada umumnya tidak melalui tahap penyamain tetapi bibit jagung berupa biji jagung langsung di tanam di tanah dengan membuatkan lubang menggunakan pacul atau kayu kemudian di tutup kembali sehingga proses penyamain juga telah mencakup proses penanaman.

\section{Penanaman Jagung}

Penanaman jagung adalah proses penanaman benih jagung atau bibit jagung yang telah disiapkan agar dapat tumbuh dan dipelihara hingga proses panen. Pada masyarakat lokal proses penanaman benih jagung yaitu dilakukan dengan membuatkan lubang dengan menggunaan cangkul atau juga biasa menggunakan lembing yang dibuat dari kayu. Proses penanaman dilakukan dalam waktu satu hari dengan cara bersama-sama dengan saling membantu antara anggota masyarakat.

\section{$>$ Perawatan Tanaman Jagung}

Tahapan selanjutnya setelah proses penanaman jagung yaitu proses perawatan tanaman jagung hingga proses panen. Perawatan tanaman jagung mencakup berbagai upaya dalam melakukan mengawasan dan pemeliharaan pada tanaman jagung dari gangguan hama, gulma dan memberian tambahan kadar makanan berupa pemberian pupuk pada tanaman jagung agar cepat tumbuh dan berkembang

serta memiliki tinggat produktfitas buah yang tinggi hingga masa panen.

Berdasarkan beberapa keterangan di atas tentang proses pemeliharaan atau perawatan pada tanaman jagung pasca penanaman maka menunjukan bahwa terdapat perbedaan antara masyarakat lokal desa Wakobalu Agung dalam melakukan perawatan terhadap tanaman jagung. Pada masyarakat lokal perwatan hanya dilakukan sebatas pada pembersihan rumput liar yang ada sikitar tanaman jagung dan sebagian masyarakatnya juga melakukan penyemprotan pada hama yang mengganggu tanaman jagung. Sedangkan pada masyarakat transmigrasi dari jawa pada tahapa pemeliharan tidak hanya sebatas pembersihan rumput liar yang ada sikitar tanaman jagung dan sebagian masyarakatnya juga melakukan penyemprotan pada hama yang mengganggu tanaman jagung tetapi juga dilakukan pemupukan pada tanaman jagung setelah proses penanaman dilakukan.

\section{> Panen Hasil Jagung}

Tahapan panen adalah merupakan hasil akhir dari usaha penanaman jagung yang dilakukan oleh petani jagung di desa Wakobalu Agung untuk memetik hasil usaha yang telah dilakukan dalam beberapa bulan berupa buah jagung yang dapat dikonsumsi atau dijual untuk memenuhi kebutuhan hidup

Berdasarkan keterangan dan penjelasan dari hasil wawancara maka dapat diketahui bahwa proses panen yang dilakukan oleh masyarakat lokal di desa 
Wakobalu Agung Kecamatan Kabangka adalah masa yang paling ditunggu oleh setiap petani jagung untuk menikmati hasil pertanianya yang telah disuahakan. Adapun tentang teknik panen terdapat

A1kesamaan yaitu menggunakan parang, sabit/arit untuk mengambil jagung dari pahonya. Namun demikian pengolahan setelah panen yaitu pemisahan biji jagung dari tongkolnya sebagian masyarakat lokal masih menggunakan caraa manual dengan tangan sedangkan sebagian besar masyarakat trnasmigrasi telah menggunakan mesin penggiling yang lebih efisien untuk memisahkan biji jagung dari tongkolnya.

Untuk mengetahui perbedaan tentang hasil pengolahan lahan pertanian pada masyarakat lokal dan masyarakat transmigrasi maka dapat dilihat pada tabel berikut:

Tabel 4.2

persamaan dan perbedaan yang dilakukan masyarakat lokal dan masyarakat transmigrasi dari jawa dalam mengelola dan mengolah lahan pertanian

\begin{tabular}{|c|c|c|c|c|c|c|c|}
\hline \multirow{4}{*}{ No. } & \multirow{4}{*}{$\begin{array}{l}\text { Indikator } \\
\text { tahapan } \\
\text { pengolahan } \\
\text { usaha } \\
\text { pertanuian } \\
\text { jagung }\end{array}$} & \multirow{3}{*}{\multicolumn{2}{|c|}{ Masyarakat Lokal }} & \multirow{3}{*}{\multicolumn{2}{|c|}{$\begin{array}{c}\text { Masya } \\
\text { rakat } \\
\text { Transmigrasi } \\
\end{array}$}} & \multirow{4}{*}{ Jumlah } & \multirow{4}{*}{ Persentase } \\
\hline & & & & & & & \\
\hline & & & & & & & \\
\hline & & Dilakukan & $\begin{array}{c}\text { Tidak } \\
\text { Dilakukan }\end{array}$ & Dilakukan & $\begin{array}{c}\text { Tidak } \\
\text { Dilakukan }\end{array}$ & & \\
\hline 1. & $\begin{array}{l}\text { Pembukaan } \\
\text { Lahan Baru } \\
\text { melakukan } \\
\text { ritual adat }\end{array}$ & 20 & & 12 & 8 & 40 & $80 \%$ \\
\hline 2. & $\begin{array}{l}\text { Pembersihan } \\
\text { lahan } \\
\text { sebelum } \\
\text { penanaman }\end{array}$ & 20 & & 20 & & 40 & $100 \%$ \\
\hline 3. & $\begin{array}{l}\text { Sebelum } \\
\text { Penanaman } \\
\text { bibit } \\
\text { diberikan } \\
\text { pestisida agar } \\
\text { benih tidak } \\
\text { diganggu } \\
\text { hama } \\
\end{array}$ & 20 & & 20 & & 40 & $50 \%$ \\
\hline 4. & $\begin{array}{l}\text { Pembibitan } \\
\text { atau } \\
\text { penyamaian }\end{array}$ & 10 & 10 & & 20 & 40 & $25 \%$ \\
\hline 5. & $\begin{array}{l}\text { Penanaman } \\
\text { benih Jagung }\end{array}$ & 20 & & 20 & & 40 & $100 \%$ \\
\hline 6. & $\begin{array}{l}\text { Pemeliharan } \\
\text { dan } \\
\text { perawatan } \\
\text { tanaman } \\
\text { jagung } \\
\end{array}$ & 20 & & 20 & & 40 & $100 \%$ \\
\hline
\end{tabular}


Jurnal Penelitian Pendidikan Geografi Volume 4 Nomor 2 April 2019

\begin{tabular}{|c|c|c|c|c|c|c|}
\hline 7. & $\begin{array}{l}\text { Pemupukan } \\
\text { tanaman } \\
\text { jagung }\end{array}$ & 20 & 4 & 16 & 40 & $60 \%$ \\
\hline 8. & $\begin{array}{l}\text { Panen hasil } \\
\text { jagung }\end{array}$ & 20 & 20 & & 40 & $100 \%$ \\
\hline 9. & $\begin{array}{l}\text { Pengolahan } \\
\text { hasil panen } \\
\text { menggunakan } \\
\text { mesin } \\
\text { penggiling } \\
\text { untuk } \\
\text { memisahkan } \\
\text { biji jagung } \\
\text { dari } \\
\text { tongkolnya }\end{array}$ & 20 & 15 & 5 & 40 & $62.5 \%$ \\
\hline
\end{tabular}

Sumber: Data diolah dari hasil wawancara 2018

\section{Pembahasan Hasil Petani Jagung dan faktor Penyebab adanya Perbedaan Hasil Petani Jagung Masyarakat Lokal dan Transmigrasi Asal Jawa di Desa Wakobalu Agung Kecamatan Kabangka Kabupaten Muna}

Pembahasan sebelumnya telah dijelaskan desa Wakobalu Agung adalah desa yang masyarakatnya terdiri dari masyarakat lokal dan masyarakat transmigrasi dari jawa. Meskipun terdiri dari masyarakat lokal dan pendatang sebagai daerah transmigran namun kehidupan masyarakatnya telah menyatu dan hidup berdampingan satu sama lainya. Kondisi ini dapat dilihat dari mata pencaharian utama dari masyarakat desa Wakobalu Agung Kecamatan Kabangka Kabupaten Muna yang umumnya adalah bertani baik dilakukan oleh masyarakat lokal maupun masyarakat pendatang atau tranmigrasi.

Sebagai salah satu usaha pertanian yang sangat dominan yang dilakukan masyarakat Wakobalu Agung adalah pertanian jagung.

Usaha pertanian jagung baik yang dilakukan oleh masyarakat lokal maupun masyarakat transmigrasi telah berjalan cukup lama, namun demikian dalam pengelolaan usaha pertanian jagung antara masyarakat lokal dan masyarakat tranmigrasi terdapat perbedaan hasil yang diperoleh oleh petani jagung. Berdasarkan data yang dipaparkan sebelumnya hasil pertanian jagung pada masyarakat lokal hanya berkisar rentan antara 100 hingga 250 $\mathrm{kg}$ permusimnya sedangkan pada masyarakat transmigrasi mendapatkan hasil pertanian jagung berkisar rentan antara 200 hingga 350 bahkan $400 \mathrm{~kg}$ permusimnya. Dari hasil tersebut maka dapat dilihat adanya perbedaan hasil yang diperoleh petani jagu pada masyarakat lokal dan masyarakat transmigrasi

\section{PENUTUP}

\section{a. Kesimpulan}

Berdasarkan hasil penelitian dan pembahasan dalam penelitian ini maka penulis menyimpulkan beberapa kesimpulan sebagai berikut:

$>$ Deskripsi produktivitas hasil pertanian jagung pada masyarakat lokal di desaWakobalu Agung Kecamatan Kabangka Kabupaten Muna hanya berkisar rentan antara 100 sampai 250 $\mathrm{kg}$ permusimnya sedangkan pada masyarakat transmigrasi dari jawa 
hasil pertanian jagung yang diperoleh setiap musimnya yaitu berkisar rentan antara 250 hingga $450 \quad \mathrm{~kg}$ permusimnya. Maka demikian terdapat perbedaan anatara hasil usaha petani jagung masyarakat lokal dan masyarakat transmigrasi asal jawa.

$>$ Perbedaan hasil pertanian jagung antara masyarakat lokal dengan masyarakat transmigrasi dipengaruhi oleh pemberian pestisida dan pupuk pada tanaman jagung oleh masyarakat transmigrasi sedangkan pada masyarakat lokal tidak dilakukan.

\section{b. Saran}

\section{Kepada Masyarakat desa Wakobalu Agung}

Masyarakat desa Wakobalu Agungkhsusunya masyarakat lokal dapat mengikuti cara dan metode pengeloaan lahan pertanian jagung yang dilakukan oleh masyarakat transmigrasi agar produktifitas pertanian jagung dapat lebih meningkat.

\section{Kepada Pihak Pemerintah}

Kepada pemerintah khusunya pemerintah daerah melalui dinas pertanian dapat turut serta berkontribusi dalam memberikan sosialisasi pada masyarakat tentang cara dan metode budidaya jagung agar lebih meningkat produktifitasnya

\section{Insan Akademik}

Kepada insan akademik agar terus mengembangkan penelitian lanjutan yang berhubungan dengan pengemabangan sumber daya dan budi daya tentang sumber ekonomi dan kebutuhan masyarakat.

\section{DAFTAR PUSTAKA}

Ari, S., Husen, Susi, S. 2016. Analisis Usaha Tani Dalam Prospek Pengembangan Kualitas Tanaman, di Desa Makmur Jaya, Kecamatan Petojo Utara, Bandung.Jurnal
Pertanian. Volume 5.Nomor 2. ISSN 9628-9836 Halaman 11

Arikunto, S. 2010. Prosedur Penelitian. Suatu Pendekatan Praktik. (Edisi Revisi). Jakarta. Indonesia.

Dilla, Anisara Nasyahta. 2014. Analisis Faktor-Faktor Yang Mempengaruhi Pengambilan Keputusan Petani Dalam Menggunakan Pupuk Organik Pada Komoditas Jagung Di Desa Wonorejo, Kecamatan Lawang, Kabupaten Malang.Skripsi. Universitas Brawijaya. Malang.

Dwiyantoro, M., S. 2007. Reformasi tata pemerintahan dan otonomi daerah. Semarang: Pusat Studi Kependudukan dan Kebijakan. Erlangga. Semarang

Harisman, K. I., R. 2014. Pengaruh Kemampuan Kerja Sama Kelompok Usaha Tani Terhadap Penerapan Teknologi Sistem Of Rice Intensification (SRI) di Kabupaten Sumedang. Jurnal Pertanian. Volume 8.Nomor 2. ISSN 19798911. Halaman 9

Hasan, 2017. Pendekatan Konsep Kemasyarakatan. Erlangga. Jakarta.

Kementerian Tenaga Kerja dan Transmigrasi RI. 2011. Konsep Pedoman perencanaan pengembangan masyarakat di permukiman transmigrasi. Jakarta: Direktorat Perencanaan Teknis Pengembangan Masyarakat dan Kawasan.

Koenjaraningrat, 2009. Keberagaman Dalam Bermasyarakat. Erlangga. Jakarta. 
Jurnal Penelitian Pendidikan Geografi Volume 4 Nomor 2 April 2019

Moehar. 2001. Pengantar Ekonomi Pertanian. Bumi Aksara: Jakarta.

Nansi. 2011. Analisis Pengambilan Keputusan Pilihan Tujuan Usaha dan Ekonomi Rumah Tangga Tani Peternak Babi Di Kabupaten Minahasa.Program Pasca Sarjana Fakultas Pertanian Universitas Gadjah Mada. Yogyakarta.

Randa, R., M. 2007. Masyarakat Madani Dalam Konsep Kehidupan Masyarakat. Jurnal Kemasyarakatan. Volume 6. Nomor 4. ISSN 8972-9981 Halaman 15

Reijntjes, Haverkort, dan Bayer. 2006. Pertanian Masa Depan, Pengantar untuk Pertanian Berkelanjutan dengan Input Luar Rendah. Yogyakarta. Kanisius.

Rifai, A. 2007. Peranan Masyarakat Lokal Dalam Melestarikan Budaya Daerah di Kota Sibuhuan, Padang Lawas. Jurnal Budaya. Volume 2. Nomor 4. ISSN 6893-7329. Halaman 5

Suratiyah, Jen., 2006. Ilmu Usaha Tani, Penerbar Swadaya. Jakarta.

Wawan, R., B. 2016. Pengolahan Lahan dan Pemanfaatan Sumberdaya Hayati. Erlangga. Jakarta.

Wiwin, S. 2009. Usaha Tani dan Prospek Jangka Panjang Dalam Ketahan Pangan. Jurnal Pangan. Volume 2. Nomor 6. ISSN 9801-9251. Halaman 7

Yuminarti, U. 2017. Kebijakan Transmigrasi Dalam Rangka Otonomi Khusus di Papua.
Masalah dan Harapan.Jurnal Kependudukan Indonesia. Volume 12. Nomor 1. ISSN 1907-2902 (Print) dan 2502-8537 (Online) Halaman 11 